\title{
Dynamic trends and driving forces of land use intensification of cultivated land in China
}

\author{
WANG Guogang ${ }^{1,2}$, LIU Yansui ${ }^{2}$, 'LI Yurui' ${ }^{2}$ CHEN Yangfen ${ }^{1}$ \\ 1. Institute of Agricultural Economics and Development, CAAS, Beijing 100081, China; \\ 2. Institute of Geographic Sciences and Natural Resources Research, CAS, Beijing 100101, China
}

\begin{abstract}
The aim of this study is to establish several important factors representing land use intensification in cultivated land (denoted by $\mathrm{ClI}$ ), using a multi-dimensional approach to achieve realistic and practical cultivated land use policies in China. For this reason, the theoretical framework was first built to explain the changes of land use intensification in the cultivated land, and then the variables and index were further developed for the purpose of characterizing the dynamic trends and driving forces of the land use intensification in the cultivated land at the provincial level. The study results indicate that the extent of CII significantly increased during the period of 1996 to 2008, due to the extensive use of fertilizers, machinery and pesticide, increased labor and capital input, and intensified land use. Moreover, the principal component regression results show that the productivity of cultivated land, economic benefits of cultivated land, labor productivity, and land use conversion are the main factors affecting the village development. The first three factors play a positive role, while the last one has a negative effect on the land use intensification in the cultivated land. According to these results, the main policies for sustainable intensification in cultivated land are proposed. First, the sustainable pathways for intensification should be adopted to reduce the unsustainable uses of chemical fertilizer, agricultural chemicals, etc. Second, the conditions for agricultural production should be further improved to increase the cultivated land productivity. Third, it is very necessary and helpful for improving labor productivity and land use efficiency from the viewpoint of accelerated the cultivated land circulation. The last step is to positively affect the production activities of peasants by means of reforming the subsidy standards.
\end{abstract}

Keywords: cultivated land; land use intensification; spatial pattern; factors; China

\section{Introduction}

Cropland is the essential component of land resources, and has many functions, such as safeguarding national food security, meeting the demands of land use for industrialization

Received: 2014-06-23 Accepted: 2014-08-20

Foundation: National Natural Science Foundation of China, No.41401203, No.41130748; Central Research Institutes of Basic Research and Public Service Special Operations, No.005201400127

Author: Wang Guogang (1984-), PhD, specialized in land sciences, agricultural economics and rural development. E-mail: caswang@126.com

*Corresponding author: Li Yurui (1983-), PhD, E-mail: liyr@igsnrr.ac.cn 
and urbanization, and ecological environmental construction (Cai and Huo, 2006). Experience accumulated by scholars throughout the world has shown that with socio-economic development cropland depletion is inevitable, and this argument is demonstrated by the changes shown in China's cropland resources. According to the 2008 bulletin of national land and resource data, in this year China's cropland area was 121.72 million hm $^{2}$, reduced by 8.3 million $\mathrm{hm}^{2}$ compared with 1996, leading to an annual reduction of 595.24 thousands $\mathrm{hm}^{2}$. The cropland red line of 120 million $\mathrm{hm}^{2}$ was in jeopardy, and the per capita cropland area only accounted for 39\% of the global average level. Through a survey on cropland transfer flow, it was found that the cropland reduction is mainly a result of reforestation, construction projects, disaster damage and agricultural structure adjustment (Zhu et al., 2007). It appears that under the current reforestation from cropland to grassland, construction occupying a large area of cropland, as well as other policies and development environments, cropland areas in China may continue to reduce. However, China is an agriculture-dominant country with a large population, where the demand for food has always been extremely high, thus leading to China's limited cropland resources undertaking large amounts of production pressures (Zhu et al., 2007), and the decline of cropland will further threaten the sustainable food security to 1/5 of the world's population (Liu and Li, 2010). The dynamic change of cropland and effective utilization degree are the key factors influencing the regional sustainable development and food security (Xu et al., 2012), which has greatly attracted the attention of the central government. The improvement in cropland use intensity and production of greater amounts of food from the same or smaller cropland areas without any increase in environmental pressure is the most effective way to safeguard China's food security in the future (Foley et al., 2011; Garnett et al., 2013; Godfray et al., 2010; Song and Ouyang, 2012).

Cropland intensive use degree refers to the capital and labor in the unit area of cropland in the production process (Huang and Zhang, 2010; Bi, 2011), which determines the yield level per unit area of cropland to a certain extent (Chen and Li, 2009). The intensive utilization of cropland may not only be related to the increase in peasants' income, but may also be related to regional sustainable development and national food security strategies (Xie et al., 2012). However, in the process of urbanization, the decline in peasants' enthusiasm of agricultural production leads to a serious and growing cropland marginalization problem (Baldock et al., 1996; Huang et al., 2010), which has attracted the attention of academic circles. Existing research focuses on the evaluation of cropland intensive utilization degree at different regional scales (Xie et al., 2012; Huang et al., 2010), thereby revealing the change law (Zhu et al., 2009), structure analysis (Zhu et al., 2007; Chen and Li, 2009), and so on. The measurement methods mainly include index evaluation method, analytic hierarchy process, factor analysis, energy analysis (Godfray et al., 2010; Xie et al., 2012; Lambin et al., 2000), and so on. The research evaluation perspectives focus on two aspects, i.e. cropland input and output, while a smaller number of discussions are carried out in the inner mechanism and driving mechanism of cropland intensive utilization.

As viewed from the microscopic perspective of peasants, cropland resource utilization is a type of peasant household behavior. Peasants are rational agents, and their selection of production input adheres to the principle of income maximization under specific cost restriction. The cropland intensive utilization degree is a result of a certain type of economic behavior 
of peasants as microscopic behavior subjects (Wu et al., 2011). Based on the above cognition, in this paper the mechanism of cropland intensive utilization is theoretically analyzed, the spatiotemporal differentiation characteristics of national provincial cropland use intensive degree is evaluated, and the key factors influencing the cropland intensive utilization under the pressure of "maintaining growth and red line" are explored. In addition, corresponding policy suggestions are obtained, so as to provide a decision-making reference for cropland protection and its intensive utilization.

\section{Analytical framework and research methods}

\subsection{Analytical framework}

Peasants are not only the basic unit of rural society, but are also the main body of cropland management. Since the implementation of household contract responsibility system, peasants have had autonomy in the operation of production as the basic unit of agricultural production decisions. With China's market economic development, the peasant household economic behaviors show a transition from survival rationality to economic rationality (Li and Fu, 2008). Moreover, the overall behavior of peasant households is more consistent with the principle of rationality, which provides a theoretical basis for the study of peasant household behaviors.

Classical economics emphasizes the fact that the division of labor is the source of economic growth, and the production specialization and division of labor lead to more rapid economic growth. In inframarginal economic theory, the division of labor is further divided into personal specialization, professional diversification, production circuitry and economic organization. In terms of the internal division of peasant households, the individual specialization of family members is consistent with the profession diversification of overall families, leading to indirect economic development, which promotes the expansion of individual peasant land management scale and the improvement in the efficiency of small-scale peasant economy, so that the multi-occupation becomes the long-term balanced organization form (Xiang and Han, 2007). In neoclassical economics, which focuses on the allocation of resources, it is considered that peasant multi-occupation hinders the improvement of agricultural labor productivity, thus reducing the land output and utilization rate without an ideal state of scale economy, which is not the most effective method of resource allocation. However, based on the cognitions of the socio-economic development stage, land expectation and social security functions, peasants are wary of land circulation, which uses surplus agricultural labor force resources to increase the income of peasants for seeking a reasonable configuration method of agricultural production elements, which is in line with the "economic rationality" decision criteria. In accordance with the "economic rationality" decision, peasants will strive consider a variety of environmental and resource conditions to configure elements, in order to obtain the maximum benefit and allocation efficiency of production factors (Li et al., 2012; Schultz, 2010). Peasants are direct land users, and their rational allocation of production factors determines the intensive utilization degree of cropland.

Based on relevant theoretical analysis, this paper argues that, even in the traditional agricultural production, peasants also seek the configuration mode of agricultural production elements to maximize their interests. Due to this element configuration concept, under the 
condition of specific productivity, the cropland input behaviors of peasants as rational economic persons are subject to benefit maximization principle, i.e. the essence of cropland intensive utilization is the benefit-maximum-based element configuration concept of peasants. The behavior results of cropland input and use are proportional to the peasants' expectations regarding cropland earnings.

\subsection{Research methods}

\subsubsection{Evaluation index and intensive utilization degree index}

According to the scientific connotation of cropland intensive utilization, the literature review and expert consultation methods are used to select the evaluation index system of cropland intensive utilization degree (Table 1). Then, based on provincial panel data from 1996 to 2008, the factor analysis and other methods are adopted to analyze the cropland intensive utilization evaluation index. The specific steps are shown as follows: (1) use the maximum difference normalization method for standardized processing of the original data; (2) carry out the use condition judgment of the factor analysis method; (3) calculate the eigenvalue and eigenvector of the correlation matrix, and extract the public factor; and (4) calculate the factor loading matrix. On this basis, the cropland intensive utilization degree index $(C I I)$ is established as follows:

$$
C I I=\sum_{i=1}^{n} F_{i} \cdot V_{i}
$$

where $F_{i}$ is the contribution rate of the $i$-th common factor, and $V_{i}$ is the variance contribution rate of the $i$-th common factor.

Table 1 Cropland intensive utilization evaluation indices and their meanings

\begin{tabular}{|c|c|c|c|}
\hline Evaluation index & Metering method & Index description & Effect \\
\hline Labor input $\left(\mathrm{V}_{1}\right)$ & Labor / Cropland area & Labor input level & + \\
\hline Fertilizer input $\left(\mathrm{V}_{2}\right)$ & $\begin{array}{l}\text { Fertilizer pure quantity / Cropland } \\
\text { area }\end{array}$ & Fertilizer input intensity & + \\
\hline Pesticide input $\left(\mathrm{V}_{3}\right)$ & Pesticide usage / Cropland area & Pesticide input intensity & + \\
\hline Mechanical input $\left(\mathrm{V}_{4}\right)$ & Mechanical power / Cropland area & Mechanical use level & + \\
\hline $\begin{array}{l}\text { Agricultural expenditure per unit } \\
\text { area of cropland }\left(V_{5}\right)\end{array}$ & $\begin{array}{l}\text { Agricultural expenditure / Crop- } \\
\text { land area }\end{array}$ & Capital input level & + \\
\hline Multiple crop index $\left(\mathrm{V}_{6}\right)$ & Total cropping area / Cropland area & Cropland use intensity & + \\
\hline $\begin{array}{l}\text { Relative abandoning index \% } \\
\left(\mathrm{V}_{7}\right)\end{array}$ & Note $^{1}$ & $\begin{array}{l}\text { Cropland intensive utiliza- } \\
\text { tion degree }\end{array}$ & - \\
\hline Cropland change rate $\left(\mathrm{V}_{8}\right)$ & $\begin{array}{l}\text { (Cropland end area - base area) / } \\
\text { Cropland end area }\end{array}$ & Cropland transition degree & - \\
\hline $\begin{array}{l}\text { Effective irrigated area propor- } \\
\text { tion }\left(V_{9}\right)\end{array}$ & $\begin{array}{l}\text { Effective irrigated area / Cropland } \\
\text { area }\end{array}$ & $\begin{array}{l}\text { Irrigation fundamental in- } \\
\text { frastructure status }\end{array}$ & + \\
\hline
\end{tabular}

${ }^{1}$ Calculation method of cropland abandoning index: $A A I_{i j}=1-M C I_{i j} / M C I i \max$, in which $A A I$ is the cropland abandoning index, $M C I$ is the multiple crop index, and $i$ and $j$ respectively represent the region and year. The $M C I_{\text {imax }}$ indicates the maximum multiple crop index value in Region $i$. The cropland abandoning index mainly reflects the intensive utilization of cropland in quantity. The greater the $A A I$ value is, the higher the cropland abandoning degree will be, otherwise it will be lower. 


\subsubsection{Driving factor selection and data processing}

From the perspective of the influencing operators' decision, natural resource factors are selected, including cropland quality $\left(\mathrm{X}_{1}\right)$, cropland area proportion $\left(\mathrm{X}_{2}\right)$, and per labor cropland area $\left(\mathrm{X}_{3}\right)$; social and economic factors selected include per capita net income of peasant farming $\left(\mathrm{X}_{4}\right)$, cropland production comparative benefit $\left(\mathrm{X}_{5}\right)$, and labor productivity $\left(\mathrm{X}_{6}\right)$; and bearing capacity factors selected include cropland non-agricultural comparative advantage $\left(\mathrm{X}_{7}\right)$, peasant agricultural productive fixed assets $\left(\mathrm{X}_{8}\right)$, and grain yield per unit area $\left(\mathrm{X}_{9}\right)$. The above are the leading driving factors of cropland intensive utilization.

Cropland quality is a natural basic condition to influence cropland intensive utilization. In general, in the case of better cropland quality, the yield will be higher under the same input conditions. Cropland quality reflects the background characteristics of regional cropland resources, measured by the cropland standard coefficient. The cropland area proportion characterizes the abundance of regional cropland, measured by the proportion of cropland area in the total regional land area. The per labor cropland area is used to reflect the scarcity of peasant agricultural production object. The per capita net income of peasant planting industry reflects the expectations of peasants in agricultural production, which is also an important representation of input ability in agricultural production. Cropland production comparative benefit affects the enthusiasm of peasant household production, and is measured by the ratio between per capita net income of the peasant planting industry and net income of the non-planting industry. Labor productivity is an important symbol of comprehensive changes in agricultural output and labor. The cropland non-agriculturalized comparative advantage is measured by the added values of the secondary and tertiary industries per unit area of residential areas and mining areas as well as the added values of cropland agriculture per unit area, which affects the land use conversion. A portion of cropland non-agricultural conversion leads to irreversible cropland change. The peasant agricultural productive fixed asset is expressed by peasant purchase data of productive fixed assets, such as draught animals, commodity animals, large and medium-sized farming tools, agriculture, forestry, animal husbandry and fishery mechanics, as defined by the National Bureau of Statistics. The calculation method of cropland standard coefficient is shown below:

$$
C L S I i j=\left(Y_{i j} \times M C I_{i j}\right) /\left(Y_{c j} \times M C I_{c j}\right)
$$

where CLSI is the cropland standard coefficient, $M C I$ is the multiple crop index, $Y$ is the grain yield per unit area, and $i, j$ and $c$ distribution respectively represent the region, year and nation.

\subsubsection{Driving force model for cropland intensive utilization}

In order to explore the driving force of cropland intensive utilization, in this paper the multivariate regression model is used to judge the relationship between cropland intensive utilization degree and various variables. The modeling steps are as follows: (1) select the index based on correlation analysis method; (2) use the multivariate statistical factor analysis method to determine the contribution rate of each variable and solve the main factor; and (3) carry out multicollinearity diagnosis on the independent variables of the main factor according to the correlation analysis results. If there are no multicollinearity between driving factors, the multivariate linear regression model is used with the following calculation equation: 


$$
Y=b_{1} X_{1}+b_{2} X_{2}+b_{3} X_{3}+b_{4} X_{4}+\cdots+b_{n} X_{n}+m
$$

where $Y$ is the estimated value calculated according to the independent variable $X$, and $b_{i}$ $(i=1,2,3 \cdots n)$ corresponds to the partial regression coefficient of $x_{j}(j=1,2,3 \cdots n)$. If a multicollinearity exists, then the following step is carried out. (4) By means of the ridge trace to calculate the value of parameter $k$, the ridge regression model is established.

\subsection{Data sources}

During the research process, the calculated basic index data mainly include more than 10 terms, such as cropland area, fertilizer usage, and effective irrigation area. The 1996-2008 provincial (excluding Hong Kong, Macao and Taiwan regions) data include the following: cropland area, rural labor force, pesticide usage and effective irrigation area, sourced from the China Rural Statistical Yearbook (1997-2009), China Population and Employment Statistical Yearbook (1997-2009) and China Agricultural Statistics (1997-2009); total planting area, added values of agriculture, secondary and tertiary industries, mechanical power and fertilizer usage data, sourced from the China Statistical Yearbook (1997-2009) and Six-decade New China Statistical Data Collection; and peasant per capita agricultural income and agricultural expenditure, sourced from the China Rural Household Survey Yearbook (1992-2009) and National Agricultural Product Cost-benefit Data Collection.

\section{Result and analysis}

In this part, we analyzed spatial differentiation pattern of cropland intensive utilization at first, and then, dynamic change characteristics of cropland intensive utilization and its driving force were explained in detail by adopting the research methods. Finally, we divided cropland utilization into four types at provincial level.

\subsection{Spatial differentiation pattern of cropland intensive utilization}

\subsubsection{Evaluation factor identification of cropland intensive utilization}

The 1996-2008 evaluation index of cropland intensive utilization is taken as a sample to run the related module of SPSS software for calculation. The results show that the KMO statistic is 0.60 , and the $p$ value of the Bartlett sphericity test is 0.000 , indicating that the research sample has passed the applicability test of the factor analysis. According to the principles that the contribution rate of the eigenvalue is more than $85 \%$ and the absolute values of the factor load are quite different, five common factors are extracted $\left(\Sigma \lambda_{i}=7.8\right)$, and the cumulative variance contribution rate is $87.0 \%$ (Table 2). Among these, the first common factor has a higher load in $V_{2}, V_{3}$ and $V_{6}$, and the second common factor has a higher load in $V_{4}$ and $V_{9}$, which can be collectively known as conservative input factors. The third common factor has a higher load in $V_{1}$ and $V_{5}$, which can respectively be referred to as labor and capital input factors. The fourth common factor has a higher load in $V_{7}$, which reflects the intensive utilization degree of cropland use intensity, and can be referred to as the use intensity factor. The fifth common factor has a higher load in the variable of cropland change rate $\mathrm{V}_{8}$, which can be referred to as the cropland conversion factor.

Based on the above analysis, it may be concluded that the conservative labor input factor 
effectively reflects the cropland intensive utilization degree, of which the variance contribution rate is $24.9 \%$; this is followed by the labor and capital input factor, use intensity factor and cropland conversion factor, which reflect the fact that the variance contribution rates of cropland intensive utilization degree are $12.0 \%$ and $11.7 \%$, respectively. These four factors can explain $89.04 \%$ of the changes in cropland intensive utilization degree, and can thus fully reflect the cropland intensive utilization degree.

Table 2 Total variance and rotated component matrix

\begin{tabular}{|c|c|c|c|c|c|c|c|c|c|c|c|}
\hline \multirow[b]{2}{*}{ Factors } & \multicolumn{2}{|c|}{ Rotated value } & \multicolumn{9}{|c|}{ Variables } \\
\hline & $\lambda$ & $\begin{array}{c}\text { Cumulative } \\
\text { variance (\%) }\end{array}$ & $\mathrm{V}_{1}$ & $\mathrm{~V}_{2}$ & $\mathrm{~V}_{3}$ & $\mathrm{~V}_{4}$ & $\mathrm{~V}_{5}$ & $\mathrm{~V}_{6}$ & $\mathrm{~V}_{7}$ & $\mathrm{~V}_{8}$ & $\mathrm{~V}_{9}$ \\
\hline 1 & 2.24 & 24.85 & 0.57 & 0.87 & 0.79 & -0.08 & 0.04 & 0.64 & -0.05 & -0.03 & 0.3 \\
\hline 2 & 1.94 & 46.41 & 0.18 & -0.07 & 0.4 & 0.89 & 0.04 & 0.47 & 0.01 & -0.04 & 0.86 \\
\hline 3 & 1.52 & 63.32 & 0.68 & 0.03 & 0.25 & 0.12 & -0.92 & 0.35 & 0.03 & -0.09 & -0.06 \\
\hline 4 & 1.08 & 75.33 & -0.12 & -0.12 & 0.04 & -0.1 & -0.07 & -0.21 & 0.99 & -0.05 & 0.11 \\
\hline 5 & 1.05 & 87.00 & 0.17 & -0.07 & 0.03 & -0.02 & 0.2 & 0.13 & -0.05 & 0.98 & -0.02 \\
\hline
\end{tabular}

\subsubsection{Spatial differentiation characteristics of cropland intensive utilization}

According to Equation (1), the comprehensive score value of provincial cropland intensive utilization is calculated. With the support of ArcGIS, the natural clustering method is used to divide the cropland intensive utilization degree into four types, i.e. extensive use area, low intensive area, moderate intensive area and high intensive area, so as to determine the spatial heterogeneity of provincial cropland intensive utilization.

The results show that China's provincial cropland intensive utilization degrees are significantly different (Figure 1). (1) In 1996, there were more extensive use areas with large area proportions, mainly distributed in the western region and three eastern provinces, i.e. Beijing, Shanghai and Guangdong; the low intensive areas have the second largest quantity, distributed in Hebei, Hubei, Guangxi, Hainan and the three northeast provinces (Heilongjiang, Jilin, Liaoning); and the moderate and high intensive areas are concentrated in the central and southern North China Plain and the middle-lower reaches of the Yangtze River Plain. In addition, Xinjiang is classified as a high intensive area of cropland use. (2) Compared
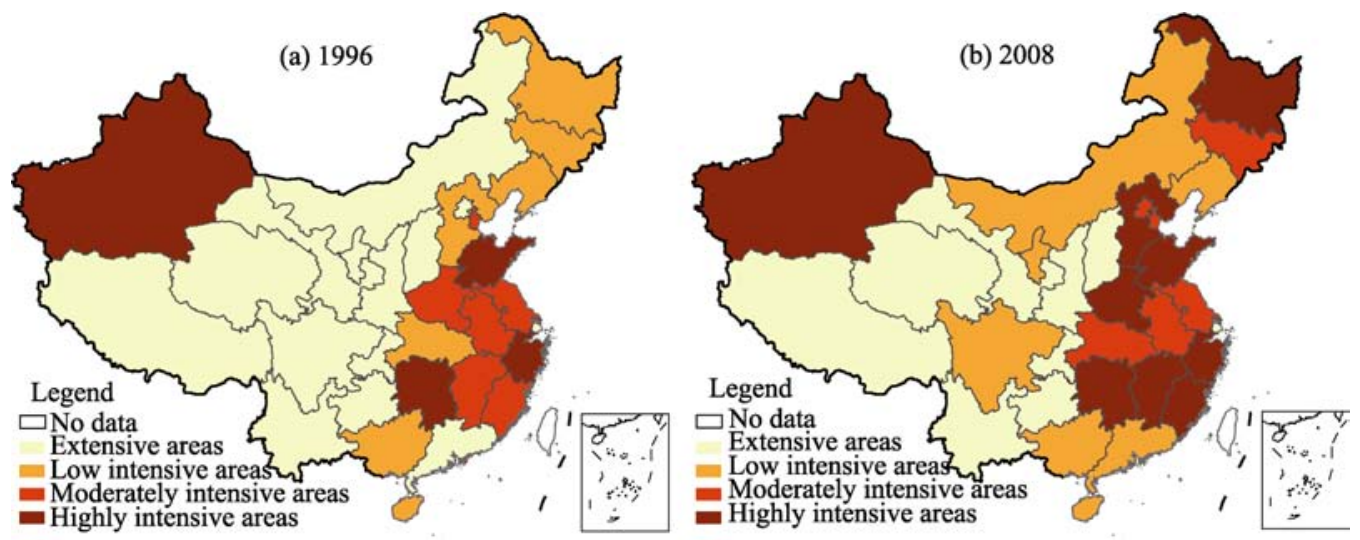

Figure 1 Spatial patterns of cultivated land intensive use during 1996-2008 at provincial level 
with 1996, the provincial cropland intensive utilization degree was greatly raised in 2008, and the provinces in extensive use areas became fewer in number with significant concentrated distribution characteristics; the moderately intensive areas are concentrated in Hubei, Anhui, Jiangsu, Beijing and Tianjin; and the highly intensive areas are significantly increased, distributed in the Huang-Huai-Hai Plain, the middle and lower reaches of the Yangtze River Plain, Xinjiang, and Heilongjiang. Provincial cropland use in 2008 basically showed a spatial differentiation pattern of "first ladder: higher intensive utilization degree and second and third ladders: lower intensive utilization degree".

\subsection{Dynamic change of cropland intensive utilization}

In order to reveal the dynamic change characteristics of provincial cropland intensive utilization degree, 31 provinces are further divided into three types, i.e. low increase speed, moderate increase speed, and high increase speed. It can be seen that the provincial cropland intensive utilization degrees were improved in 1996-2008 (Figure 2). The low increase areas are concentrated in the western region; moderate increase areas are mainly distributed in eastern China, central China, and Gansu, Ningxia, Chongqing and Guizhou provinces in the western region; and the high increase areas are concentrated in the northeast Heilongjiang-Jilin, Beijing-Tianjin, and Shanxi-Shaanxi-Ningxia-Inner Mongolia resource areas.

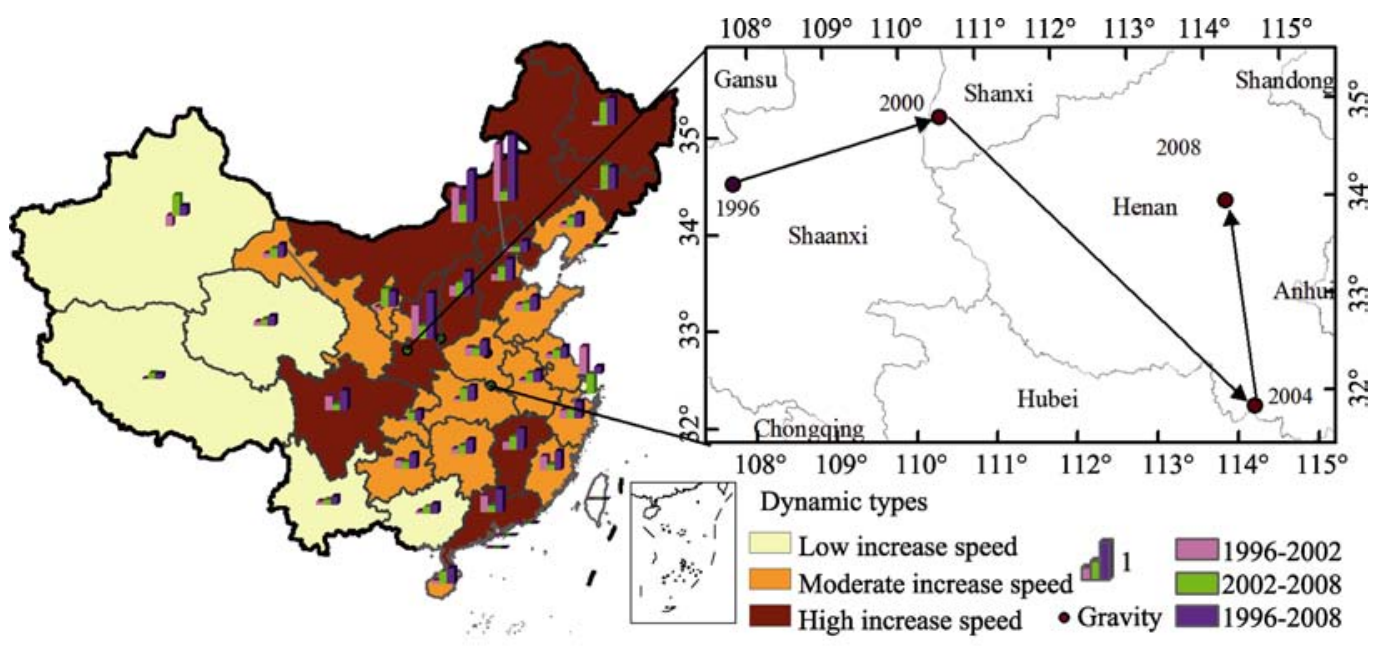

Figure 2 Dynamic pattern of cultivated land intensive use and shift of its gravity centers during 1996-2008

According to the element gravity model, the gravities of cropland intensive utilization degree in 1996, 2000, 2004 and 2008 are calculated. It can be seen from Figure 2 that the gravity of provincial cropland intensive utilization degree experienced a rapid transition from the central-western regions to the central-eastern regions in 1996-2000, after which it moved toward the southeast in 2000-2004, then quickly moved northward in 2004-2008. It is shown that in 1996-2008, the cropland intensive utilization degree in the western regions was ascending slowly, while in the central-eastern regions, especially in the northern regions, the cropland intensive utilization degree was rising greatly, and was significantly higher than that in the south. 


\subsection{Driving force analysis of cropland intensive utilization}

\subsubsection{Main impact factors of cropland intensive utilization}

At first, a normal distribution test is carried out on the data, and then the related analysis method is used to judge the relationship between cropland intensive utilization degree and each variable (Table 3 ). The results show that $\mathrm{X}_{1}, \mathrm{X}_{4}, \mathrm{X}_{5}, \mathrm{X}_{6}, \mathrm{X}_{7}$ and $X_{9}$ have significant correlations with cropland intensive utilization degree $(Y)(\mathrm{P}<0.001)$, and $X_{2}, X_{3}$ and $X_{8}$ have low correlations with $Y$ in an undetermined state. Therefore, the impacts of cropland area proportion $\left(X_{2}\right)$, per labor cropland area $\left(X_{3}\right)$ and peasant agricultural productive fixed assets $\left(X_{8}\right)$ on cropland intensive utilization degree can be excluded.

Table 3 The results of correlation analysis

\begin{tabular}{|c|c|c|c|c|c|c|c|c|c|c|}
\hline Variables & $\mathrm{Y}$ & $\mathrm{X}_{1}$ & $\mathrm{X}_{2}$ & $\mathrm{X}_{3}$ & $\mathrm{X}_{4}$ & $\mathrm{X}_{5}$ & $\mathrm{X}_{6}$ & $\mathrm{X}_{7}$ & $\mathrm{X}_{8}$ & $\mathrm{X}_{9}$ \\
\hline $\mathrm{Y}$ & 1 & & & & & & & & & \\
\hline $\mathrm{X}_{1}$ & $0.605^{* *}$ & 1 & & & & & & & & \\
\hline $\mathrm{X}_{2}$ & $0.147^{*}$ & $0.317^{* *}$ & 1 & & & & & & & \\
\hline $\mathrm{X}_{3}$ & $-0.125^{*}$ & $-0.477^{* *}$ & $-0.178^{* *}$ & 1 & & & & & & \\
\hline $\mathrm{X}_{4}$ & $0.408^{* *}$ & -0.017 & $0.148^{* *}$ & $0.545^{* *}$ & 1 & & & & & \\
\hline $\mathrm{X}_{5}$ & $0.529^{* *}$ & $-0.276^{* *}$ & -0.1 & $0.689^{* *}$ & $0.625^{* *}$ & 1 & & & & \\
\hline $\mathrm{X}_{6}$ & $0.643^{* *}$ & $0.160^{* *}$ & 0.049 & $0.275^{* *}$ & $0.563^{* *}$ & 0.038 & 1 & & & \\
\hline $\mathrm{X}_{7}$ & $-0.469^{* *}$ & $-0.358^{* *}$ & $-0.323^{* *}$ & $0.347^{* *}$ & -0.058 & 0.107 & -0.052 & 1 & & \\
\hline $\mathrm{X}_{8}$ & 0.01 & $-0.403^{* *}$ & $-0.367^{* *}$ & $0.516^{* *}$ & $0.390^{* *}$ & $0.343^{* *}$ & $0.233^{* *}$ & $0.454^{* *}$ & 1 & \\
\hline $\mathrm{X}_{9}$ & $0.580^{* *}$ & $0.764^{* *}$ & $0.262^{* *}$ & $-0.182^{* *}$ & $0.210^{* *}$ & -0.106 & $0.458^{* *}$ & $-0.151^{* *}$ & 0.046 & 1 \\
\hline
\end{tabular}

Through KMO and a Bartlett sphericity test, the five driving factors are shown to be in accordance with the requirements of the factor analysis. The calculation results show that the cumulative variance contribution rate of the extracted first four common factors reaches 94.63\%, indicating that these four common factors can fully explain the changes in cropland intensive utilization degree. Based on this, the common factors are determined, and varimax rotation is carried out to solve the principal factor solution. The results are shown in Table 4.

It can be seen from Table 4 that the first common factor has a higher correlation with cropland quality $\left(\mathrm{X}_{1}\right)$ and grain yield per unit area $\left(\mathrm{X}_{9}\right)$, reflecting the cropland productivity conditions and representing the influence of cropland natural background conditions on the cropland intensive utilization degree. The second common factor has a correlation with the per capita net income of peasants in the planting industry $\left(\mathrm{X}_{4}\right)$ and cropland production comparative benefit $\left(\mathrm{X}_{5}\right)$, representing the influence of cropland economic benefits, i.e.

Table 4 Rotated factor loading matrix

\begin{tabular}{ccccccc}
\hline Factors & $\mathrm{X}_{1}$ & $\mathrm{X}_{4}$ & $\mathrm{X}_{5}$ & $\mathrm{X}_{6}$ & $\mathrm{X}_{7}$ & $\mathrm{X}_{9}$ \\
\hline 1 & 0.925 & 0.055 & -0.13 & 0.188 & -0.148 & 0.913 \\
2 & -0.134 & 0.758 & 0.963 & 0.072 & 0.025 & 0.016 \\
3 & -0.015 & 0.568 & -0.046 & 0.962 & -0.018 & 0.306 \\
4 & -0.242 & -0.078 & 0.075 & -0.005 & 0.985 & 0.011 \\
\hline
\end{tabular}


peasant household production expectations for cropland intensive utilization degree. The third common factor has a higher correlation with labor productivity $\left(\mathrm{X}_{6}\right)$, representing the influence of peasant ability access to consumer goods on the cropland intensive utilization degree. The fourth common factor has a higher correlation with cropland non-agriculturalization comparative benefit $\left(\mathrm{X}_{7}\right)$, representing the influence of cropland use conversion.

\subsubsection{Regression equation of driving force}

It can be seen from Table 3 that a stronger correlation exists between partial variables, e.g. the correlation coefficients between $X_{1}$ and $X_{9}, X_{5}$ and $X_{3}$, and $X_{5}$ and $X_{4}$ respectively reach $0.76,0.69$ and 0.63 , indicating significant multicollinearity. Therefore, the ridge regression method is adopted in this paper. Through mapping the ridge trace, the $\mathrm{k}$ value is calculated

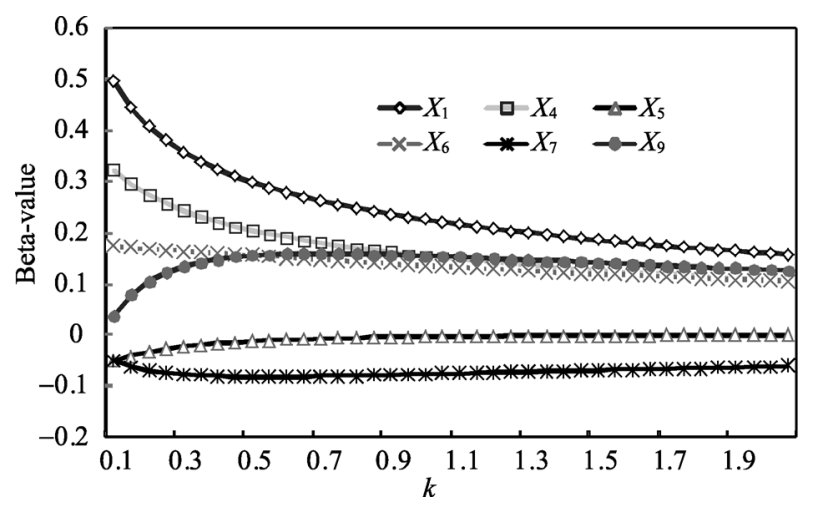

Figure 3 Ridge trace of driving factors of cultivated land intensive use to establish the regression model, so as to reduce the influence of multicollinearity on the regression results (Figure 3).

It can be seen from Figure 3 that when $k<0.8$, the ridge regression line fluctuates greatly, and the regression coefficients of various driving factors are not stable. When $k>$ 0.8 , the ridge regression line gradually tends to be gentle. Therefore, in this paper the $k$ value is set as 0.8 , and the following regression model

is obtained as follows:

$$
\begin{aligned}
& Y=-0.75+0.49 X_{1}+0.31 X_{4}+0.29 X_{5}+0.25 X_{6}-0.46 X_{7}+0.33 X_{9} \\
& t=12.16 \quad 8.30 \quad 1.14 \quad 6.11 \quad-3.10 \quad 8.66 \\
& \left(\bar{R}^{2}=0.767 ; R^{2}=0.781 ; D F=56.01 ; P=0.0000\right)
\end{aligned}
$$

The determination coefficient of the model can reach 0.781 , which indicates that driving factors can explain $78.1 \%$ of the changes in the cropland intensive utilization degree $(Y)$. The regression model results show that only $X_{7}$ has a negative correlation with $Y$, suggesting that the higher the regional cropland non-agriculturalized efficiency is, the higher the expectations of cropland use conversion will be, thus leading to non-strong cropland protection enthusiasm, reduced farming input, and lower cropland intensive utilization degree. Cropland quality, per capita net income of peasants in the planting industry, labor productivity, cropland production comparative benefit and grain yield per unit area have a significantly positive influence on cropland intensive utilization, showing that the better the cropland natural foundation conditions are, the higher the cropland production yield will be, and the more tending to intensive utilization the cropland will be; otherwise, extensive use will result. Therefore, the research hypothesis proposed in this paper is validated herein.

\subsection{Partition of cropland intensive utilization type}

In the provincial scale, according to provincial cropland intensive utilization degree from 1996 to 2008 and the change characteristics in 1996-2002, 2002-2008 and 1996-2008, the 
SPSS clustering method is used for classification. The results show that the study area can be divided into four types (Figure 4): (1) Region I is comprised of six provinces in eastern China, three provinces in central China, as well as Tianjin, Hebei and Xinjiang, of which the cropland intensive utilization degree reaches the maximum. The main reason for this is that the agricultural production mechanization degree is high in Xinjiang, where the labor productivity and cropland production comparative benefit reach a higher level, thus promoting cropland intensive utilization. This type of province is concentrated in the North China Plain and the middle and lower reaches of the Yangtze River Plain, characterized by strong basic farming conditions, abundant precipitation, and abundant agricultural labor force, but at the same time large conservative labor input exists. In addition, agricultural production activities pose serious environmental problems. (2) Region II consists of the three northeast provinces and Sichuan Province, which are characterized by very superior cropland productivity and natural conditions, as these provinces form China's important production base of agricultural products with higher agricultural labor productivity and cropland intensive utilization degree. (3) Region III is composed of three resource-enriched provinces, i.e. Shanxi, Shaanxi and Inner Mongolia, which are characterized by fragile ecological environment, poorer cropland quality, farming-pastoral intersection and serious cropland degradation. With the progress of agricultural technology, although the cropland intensive utilization degree has increased by a certain extent, the overall level is still low. (4) Region IV covers Gansu, Ningxia, Qinghai, Tibet, Yunnan, Guizhou, Chongqing and Guangxi in the western regions, and Beijing, Shanghai, Guangdong and Hainan on the east coast, characterized by poorer cropland productivity and natural production conditions, as well as lower cropland production yield, especially in the western provinces, leading to the cropland intensive utilization degree always being at a lower level.

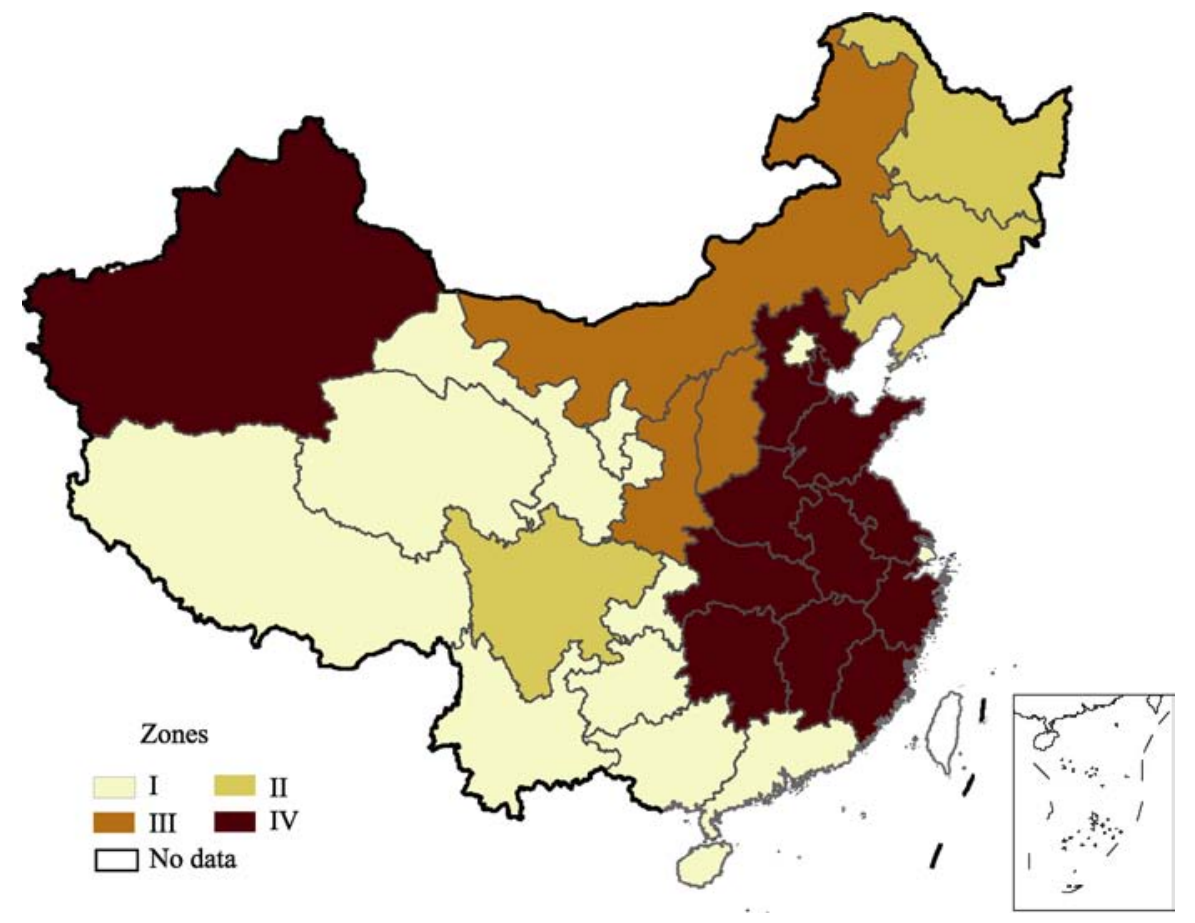

Figure 4 Divisions of cultivated land intensive use during 1996-2008 at provincial level 


\section{Conclusions and discussion}

\subsection{Conclusions}

(1) Based on "rational peasants" and informarginal economics theory, the mechanism of cropland intensive utilization is explained. In a certain divided organization structure, the peasants are in accordance with the "economic rationality" decisions to consider all types of environment and resource conditions and configure production factors as much as possible, in order to obtain the greatest benefit. As a result, the cropland production configuration method of peasants determines the cropland intensive utilization degree.

(2) The conservative input factors, such as fertilizers, machinery and pesticides, are the greatest reflection of cropland intensive utilization degree, followed by the labor and capital input factor, utilization intensity factor, and cropland conversion factor. These four factors can explain $89.04 \%$ of the changes in the cropland intensive utilization degree.

(3) In the spatial and temporal scales, compared with 1996, the provincial cropland intensive utilization degree was greatly raised in 2008 with significant regional differences, initially showing a spatial differentiation pattern of "the first ladder: higher intensive degree, and the second and third ladders: lower intensive degree”. Among these, the natural background conditions of croplands are the first positive driving factors influencing the cropland intensive utilization degree. In addition, the higher the cropland production comparative benefit and labor productivity are, the more tending to intensive utilization the cropland will be. However, the higher the regional cropland non-agriculturalized efficiency is, the more unfavorable to intensive utilization the cropland will be.

\subsection{Policy discussion}

The above research conclusions show the following beneficial policy implications: (1) Financial support can be increased, and agricultural production conditions, such as comprehensive improvement of field, water, road and forest, can be improved to construct high standard farmland and improve the middle- and low-yielding fields, so as to improve the overall cropland production capacity and promote more intensive utilization of cropland. (2) As viewed from the perspective of the positive influence of labor productivity on cropland intensive utilization, it is recommended to accelerate the formulation and perfection of the cropland circulation system, cultivate new agricultural management object and new-type peasants, integrate production factors, and improve labor productivity. This will provide policy guidance for regions with poor basic cropland conditions or higher cropland non-agriculturalized efficiency, to effectively solve cropland abandonment, low use efficiency, and other problems. (3) The inputs of fertilizers, pesticides and other non-renewable resources in agricultural production are important characterizations of a rise in cropland intensive utilization. However, based on the cognition of their impacts on ecological environment, this should be considered dialectically. It is urgently required to strengthen policy guidance for scientific and reasonable use. (4) Tasks which should be performed are improve agricultural pricing, strengthen the research and implementation of direct subsidy policies for grain producers and agricultural material subsidy policies, perfect the compensation mechanism, optimize farming system and the subsidy systems, raise subsidy standards, reduce agricultural production costs, and improve the comparative benefits of agricultural 
production and peasant enthusiasm in farming production. In addition, it is necessary to be wary of excessive cropland non-agriculturalization and non-food phenomena resulting from the lower cropland production comparative benefits.

\section{References}

Baldock D, Beaufoy G, Brouwer F et al., 1996. Farming at the Margins: Abandonment or Redevelopment of Agricultural Land in Europe. London and The Hague: Institute for European Environmental Policy/Agricultural Economics Research Institute.

Bi Baode, 2011. Land Economics. Beijing: China Renmin University Press. (in Chinese)

Cai Yunlong, Huo Yaqin, 2006. Reevaluating cultivated land in China: Method and case studies. Acta Geographica Sinica, 61(10): 1084-1092. (in Chinese)

Chen Jianfei, Wei Suqiong, Chang Kangtsung et al., 2007. A comparative case study of cultivated land changes in Fujian and Taiwan. Land Use Policy, 24(2): 386-395.

Chen Yuqi, Li Xiubin, 2009. Structural change of agricultural land use intensity and its regional disparity in China. Acta Geographica Sinica, 64(4): 469-478. (in Chinese)

Foley J A, Ramankutty N, Brauman K A et al., 2011. Solutions for a cultivated planet. Nature, 478(7369): 337-342.

Garnett T, Appleby M C, Balmford A et al., 2013. Sustainable intensification in agriculture: Premises and policies. Science, 341(6141): 33-34.

Godfray H C J, Beddington J R, Crute I R et al., 2010. Food security: The challenge of feeding 9 billion people. Science, 327: 812-818.

He Xiaoqun, Liu Wenqing, 2007. Applied Regression Analysis. 2nd edn. Beijing: China Renmin University Press. (in Chinese)

Huang Jikun, Wang Xiaobing, Zhi Huayong et al., 2010. Subsidies and distortions in China's agriculture: Evidence from producer-level data. The Australian Journal of Agricultural and Resource Economics, 55(1): 53-71.

Huang Xianjin, Zhang Anlu, 2010. Land Economics. Beijing: China Agricultural University Press. (in Chinese)

Lambin E F, Rounsevell M D A, Geist H J, 2000. Are agricultural land-use models able to predict changes in land-use intensity? Agriculture, Ecosystems and Environment, 82: 321-331

Li Hongtao, Fu Shaoping, 2008. “The Rational Peasant” or “moral economy”: Review and new interpretation. Social Sciences Review, 23(5): 39-41. (in Chinese)

Li Xiaojian, Zhou Xiongfei, Zheng Chunhui et al., 2012. Development of specialized villages in various environments of less developed China. Acta Geographica Sinica, 67(6): 783-792. (in Chinese)

Liu Yansui, Li Yurui, 2010. Spatio-temporal coupling relationship between farmland and agricultural labor changes at county level in China. Acta Geographica Sinica, 65(12): 1602-1612. (in Chinese)

Schultz T W, 2010. Transforming Traditional Agriculture. Liang Xiaoming, trans. Beijing: The Commercial Press. (in Chinese)

Song Xiaoqing, Ouyang Zhu, 2012. Key influencing factors of food security guarantee in China during 1999-2007. Acta Geographica Sinica, 67(6): 793-803. (in Chinese)

Wu Yuling, Feng Zhonglei, Zhou Yong et al., 2011. Co-integration analysis on driving factors of intensive cultivated land use based on perspective of farmers: A case study of Hubei Province. China Population Resources and Environment, 21(11): 67-72. (in Chinese)

Xiang Guocheng, Han Shaofeng, 2007. Division of labor and agricultural organizational evolution: An analysis based on the model of indirect pricing theory. China Economic Quarterly, 6(2): 513-538. (in Chinese)

Xie Hualin, Zou Jinlang, Peng Xiaolin, 2012. Spatial-temporal difference analysis of cultivated land use intensity based on emergy in Poyang Lake Eco-economic Zone. Acta Geographica Sinica, 67(7): 889-902. (in Chinese)

Xu Hengzhou, Guo Yuyan, Wu Guancen, 2012. Influence of farmer differentiation on cultivated land use efficiency. Chinese Rural Economy, (6): 32-41. (in Chinese)

Zhu Huiyi, Li Xiubin, Xin Liangjie, 2007. Intensity change in cultivated land use in China and its policy implications. Journal of Natural Resources, 62(6): 907-915. (in Chinese)

Zhu Xiaoqian, Cheng Jiumiao, Fei Luocheng, 2009. Analysis on intensive use of cultivated land and its driving forces in Anhui Province. China Land Science, 23(2): 11-17. (in Chinese) 